\title{
Sources of funding as an influence on alcohol studies
}

\author{
Robin Room ${ }^{1,2}$ \\ ${ }^{1}$ Centre for Alcohol Policy Research, La Trobe University, Melbourne, Victoria, Australia \\ ${ }^{2}$ Centre for Social Research on Alcohol and Drugs, Stockholm University
}

When I first read Thomas Kuhn's (1962) seminal work, shortly after its first publication, I was awakened to the historical evidence that even the "hardest" science is a human construction deeply influenced by the social order and the conceptual traditions in which the scientist works. On the other hand, as constructivism took hold in sociology, I realized I was a "soft” constructivist, willing to acknowledge that our conceptual and other constructions face some limits from the physical world and its operating rules (Room, 1984). But in fields like ours, the constraints are quite broad, so that what constitutes alcohol social science-what its research questions are, and how it approaches them-has varied a great deal over the last century or so, and varies considerably among the societies which have been willing to fund such research. I remember discovering that temperance-oriented survey studies, when they turned attention at all beyond the boundary between drinker and abstainer, focused only on frequency of drinking, ignoring amount per occasion (Lindgren, 1973) a pattern found also in drug war-era drug surveys. What we collect as material for study and what we focus on in analyzing it are deeply influenced by our intellectual and cultural-political heritage and environment.

They are also influenced more directly by the research's sources of funding. Most of us who choose research as a job must rely on some entity to fund us. Particularly in a field like ours, which is not of central interest to any traditional academic discipline or profession, the funding is usually given within a frame of the institutional interests of the funder. This is most often a government department or research fund. Less commonly, it may be a charitable organization. Or it may be a commercial organization with interests in the field.

Some research projects supported by the industry quite directly serve the interests of the industry. For instance, a British anthropologist was recently funded by Lion Breweries to produce and publicize for Australian and New Zealand audiences a research report reviewing the literature on alcohol's role in violence, essentially with the argument that, because there are cultural differences in how people act when intoxicated, alcohol cannot be seen as a causal factor in the occurrence of violence (Fox, 2015; Miller, 2015). In these countries, where there have been successful efforts to reduce rates of late-night street violence by closing bars and clubs earlier (Kypri, McElduff, \& Miller, 2014; Menéndez, Weatherburn, Kypri, \& Fitzgerald, 2015), the report obviously had direct relevance to the alcohol industry's economic interests.

While research funding by the alcohol industry is often not so obviously tied to immediate economic interests, funding studies by prestigious researchers-especially biological and clinical researchers - can also serve an industry's interest in being seen as a "good corporate citizen," which the industry hopes will help in its lobbying efforts. The industry's approach seems to have been more to fund research in areas where the results may be helpful to their interests than to try to influence the results of studies it funds. Thus a recent analysis comparing findings on alcohol and cardiovascular disease found only equivocal evidence for any difference in results between industryfunded and other studies (McCambridge \& Hartwell, 2015).

In recent decades there has been substantially more recognition in the scientific community of the potential influence of funding sources on research. As a result, it is now routine for research journals to require that sources of funding be disclosed in the published article. While this is a sensible requirement, it must be recognized that funders are not the only sources of influence on research, and indeed that funders vary in whether and how much they influence research they have funded.

The question that alcohol researchers sooner or later face is whether to seek or accept funding from particular sources. It seems to me there are several main considerations for the researcher in deciding this:

- the degree of autonomy which the researcher or research group has in carrying out and reporting the research;

- the extent to which the researcher has the right to publish the results of the research within a reasonable timeframe and to publish further analyses from the research data; and 
- $\quad$ the threat to the researcher's reputation from accepting research money from the particular source.

Norms have shifted on this last question in the decades I have been working in the field. In the 1960s, at least in English-speaking countries, there was not much reputational damage to a researcher from accepting funding from alcohol industry-related foundations. Now the alcohol field is becoming more like the tobacco field, in which a bright line splits the field between researchers who have accepted tobacco industry money and those who will not. On this matter, my advice to young scientists has been to take into account their future reputation in deciding whether to accept industry funding, particularly given the direction in which the field has been changing concerning reputational damage.

Complicating the situation is the fact that the balance in decisions on reputational risk clearly differs between countries. In many countries there is no substantial alternative to industry-connected funding for social alcohol research. In my view, the funding situation in such a country should be taken into account in judgements about decisions made by researchers there. In the end, anyway, research should be judged by its inherent quality and contribution to knowledge. Only where the probity of the research team and results is in doubt does the issue of source of funding come to the fore in assessing the study.

That all sources of funding are potential sources of influence on our research should also be kept in mind. What research is funded by governments is constrained by policy decisions, and often also shaped by the current orthodoxies as expressed by members of grant review committees. The government interest in revenue tied to alcohol sales or in the growth of a national industry - for instance, wine - may influence its decisions on research funding, though this seems to be a rarer occurrence in the alcohol field than, say, for gambling research (Room, 2005; 2016), where influence on research by government funders is often as problematic as private industry influence (Livingstone \& Adams, 2016). Alcohol industry interests have certainly influenced government decisions on alcohol policy agencies, including the framing of research funding programs, but this influence is more likely to be expressed in closed-door political lobbying than in efforts to influence grant making decisions and processes (Room, 2006).

As noted above, influences which shape research extend beyond funding sources. The researcher him/herself is the strongest source of potential bias in the findings. In my own work, the ethic I try to keep to is distinguishing between my role as a publicly-supported technician of social policy ("if you pull this policy lever, this is the evidence on what will happen") and my role as citizen ("This is what I think should be done"). Quite often my political views on what should happen and the research evidence on what will happen are not in agreement. Those of us, whose research is publicly funded, in my view, have a duty to try to distinguish between the two roles, and to answer in the technician role to public authorities and in public discourse when asked technical questions on what happens when the lever is pulled.

\section{References}

Fox, A. (2015). Understanding behaviour in the Australian and New Zealand night-time economies: an anthropological study. Silverwater, NSW: Lion Beer, Spirits and Wine Australia. http://www.lionco.com/content/u12/Dr\%20Anne\%2 0Fox\%20report.pdf

Kuhn, T. (1962). The structure of scientific revolutions. Chicago, IL, United States: University of Chicago Press.

Kypri, K., McElduff, P., \& Miller, P. (2014). Restrictions in pub closing times and lockouts in Newcastle, Australia five years on. Drug and Alcohol Review, 33(3), 323-326.

Lindgren, Å. (1973). Some results from an international series of drinking surveys. Drinking and Drug Practices Surveyor, 8, 34-45.

Livingstone, C., \& Adams, P. (2016). Clear principles are needed for integrity in gambling research. Addiction, 111, 5-10.

Mäkelä, K., \& Viikari, M. (1977). Notes on alcohol and the state. Acta Sociologica, 20(2), 155-179.

McCambridge, J., Hartwell, G. (2015). Has industry funding biased studies of the protective effects of alcohol on cardiovascular disease? A preliminary investigation of prospective cohort studies. Drug and Alcohol Review, 34(1), 58-66.

Menéndez, P., Weatherburn, D., Kypri, K., \& Fitzgerald, J. (2015). Lockouts and last drinks: the impact of the January 2014 liquor licence reforms on assaults in NSW, Australia. Crime and Justice Bulletin, 183. http://www.bocsar.nsw.gov.au/Documents/CJB/CJB 183.pdf

Miller, P. (2015). The alcohol industry and their merchants of doubt. Posting on Drinktank website. Canberra, Australia: FARE. http://drinktank.org.au/ 2015/03/merchants-of-doubt/

Room, R. (1984). Alcohol problems and the sociological constructivist approach: quagmire or path forward? Presented at the Alcohol Epidemiology Section meetings of the International Council on Alcohol and Addictions, Edinburgh, Scotland, 4-8 June. http://www.robinroom.net/quagmire.pdf

Room, R. (2005). The wheel of fortune: Cycles and reactions in gambling policies. Addiction, 100, 1226-1227.

Room, R. (2006). Advancing industry interests in alcohol policy: The double game. Nordisk Alkohol- \& Narkotikatidskrift, 26, 389-402.

Room, R. (2016). Integrity without extinction: Paths forward for gambling research, Addiction, 111, 1117. 